PIWULANG: Jurnal Pendidikan Agama Islam, Vol. 3 No. 1 September 2020, 65-74

P-ISSN : 2622-5638. E-ISSN : 2622-5654

Homepage: http://e-journal.staima-alhikam.ac.id/index.php/piwulang

\title{
URGENSI PENDIDIKAN ISLAM DALAM MEMPROGRESIVITASKAN SUMBERDAYA MANUSIA DI ERA PANDEMI CIOVID-19
}

\author{
Muzamil \\ STAI Ma'had Aly Al-Hikam Malang \\ Email: muzamilzaini099@gmail.com
}

\begin{abstract}
There is no society and nation in this world that does not consider education, let alone Islamic education is urgent. Are facing whatever conditions this society and nation have, its dependence on Islamic education as a very high need, which is intended for the formation of human resources. From the human resources that are formed, society and the nation can show their expectations. The challenge of implementing Islamic education is faced with the reality of the development of a society and nation that is being tested by the Covid-19 pandemic, while the demand to continue to develop or progressive human resources is also a must. The development of the Covid-19 pandemic, which is still uncertain when it will end, makes the work of Islamic education providers tougher.
\end{abstract}

\section{ABSTRAK}

Tidak ada masyarakat dan bangsa di dunia ini yang tidak menganggap pendidikan, apalagi pendidikan Islam ini penting (urgen). Sedang menghadapi kondisi apapun masyarakat dan bangsa ini, ketergantungannya pada pendidikan Islam sebagai kebutuhan sangat tinggi, yakni diperuntukkan bagi pembentukan sumberdaya manusia. Dari sumberdaya manusia yang terbentuk ini, masyarakat dan bangsa bisa menunjukkan ekspektasinya. Tantangan penyelenggaraan pendidikan Islam ini dihadapkan dengan realitas perkembangan masyarakat dan bangsa yang sedang diuji pandemi Covid-19, sementara itu tuntutan tetap mengembangkan atau memprogresifitaskan sumberdaya manusia juga suatu keharusan. Perkembangan pandemi Covid-19 yang masih belum ada kepastian kapan berakhirnya membuat pekerjaan penyelenggara pendidikan Islam menjadi lebih berat.

Kata Kunci: Pendidikan Islam, Sumber Daya Manusia, Progresivitas 
PIWULANG: Jurnal Pendidikan Agama Islam, Vol. 3 No. 1 September 2020, 65-74

P-ISSN : 2622-5638. E-ISSN : 2622-5654

Homepage: http://e-journal.staima-alhikam.ac.id/index.php/piwulang

\section{A. PENDAHULUAN}

Dalam Pasal 4 UU Nomor 20 Tahun 2003 tentang Sistem Pendidikan Nasional disebutkan mengenai prinsip pendidikan, bahwa pendidikan diselenggarakan secara demokratis dan berkeadilan serta tidak diskriminatif dengan menjunjung tinggi hak asasi manusia, nilai keagamaan, nilai kultural, dan kemajemukan bangsa.

Norma itu menunjukkan, bahwa dalam kondisi apapun, termasuk di era pandemi Covid-19 ini, penyelenggaraan pendidikan harus berjalan dengan mengutamakan perlindungan atau menjunjung tinggi hak asasi subyek didik (sumberdaya manusia). Hal ini juga menunjukkan betapa urgensinya penyelenggaraan pendidikan yang benar dalam pembentukan sumberdaya manusia.

Sampai naskah ini ditulis, perkembangan Covid-19 masih mengkhawatirkan. Manusia Indonesia mulai dari orang dewasa hingga anak-anak, banyak yang terkena Covid-19. sementara disisi lain, penyelenggaraan pendidikan, termasuk pendidikan Islam masih mengandalkan cara yang tidak mengharuskan tatap muka atau dengan sistem online (daring).

Syed Sajjad Husain dan Syed Ali Ashraf menyampaikan pikirannya, bahwa pendidikan Islam merupakan suatu pendidikan yang melatih perasaan murid-murid dengan cara begitu rupa sehingga dalam sikap hidup, tindakan, keputusan, dan pendekatan mereka terhadap segala jenis pengetahuan, mereka dipengaruhi sekali oleh nilai spiritual dan sangat sadar akan nilai etis Islam ${ }^{1}$. Kalau memahami pernyataan ini, tentulah menjadi tidak ringan yang dihadapi oleh penyelenggaraan pendidikan Islam, karena ia mengimplementasikan suatu proses yang membawa misi mulia yang diharapkan dapat memberikan perubahan besar dalam kehidupan umat manusia.

Dengan kondisi proses pembalajaran yang masih seperti (tidak mengandalkan tatap muka) seperti sekarang ini, bagaimana bisa pendidikan Islam menjalankan misinya dalam membangun dan memprogresifitas (mengembangkan) sumberdaya manusia? Apa yang seharusnya dilakukan oleh kalangan penyelanggara pendidikan dalam menyikapi perubahan serius di tanah air dan bahkan dunia akibat Covid19 ?

\footnotetext{
${ }^{1}$ Syed Sajjad Husain dan Syed Ali Ashraf, Crisis Muslim Education., Terj. Rahmani Astuti, Krisis Pendidikan Islam, Risalah, 1986, hal. 2.
} 
PIWULANG: Jurnal Pendidikan Agama Islam, Vol. 3 No. 1 September 2020, 65-74

P-ISSN : 2622-5638. E-ISSN : 2622-5654

Homepage: http://e-journal.staima-alhikam.ac.id/index.php/piwulang

\section{B. PEMBAHASAN}

\section{1) Falsafah Pendidikan Islam}

Pendidikan merupakan salah satu sektor penting atau strategis dalam kehidupan masyarakat dan bangsa. Pentingnya pendidikan ini dapat terbaca diantarnya dari maju mundurnya masyarakat dan bangsa itu. Ketika yang bisa diraihnya adalah kemajuan, maka hal ini menunjukkan penyelenggaran pendidikannya baik atau ditangani dengan manajemen modern (profesionalitas). Secara tidak langsung, dengan tajam Rahman mengingatkan, bahwa seseorang yang terdidik, ditangannya tergenggam dunia, seseorang yang menyerah pada kebodohan, berarti menyerah dalam hegemoni dan keterjajahan. Keterjajahan hanya pantas disandang oleh masyarakat atau bangsa yang "memusuhi" hak pendidikan. ${ }^{2}$ Peringatan ini menunjukkan besarnya pengaruh pendidikan, sehingga bangsa manapun dilarang mengabaikannya.

Pandangan Rahman tersebut juga menjadi penguatan opini atau penilaian masyarakat yang menyebut, bahwa dunia pendidikan itu dunia mendasar, asasi, atau fundamental bagi masyarakat dan bangsa. Dalam sisi ini logis jika secara filosofis memunculkan pertanyaan, mengapa pendidikan menjadi kepentingan asasi bagi kehidupan manusia, masyarakat, dan bangsa?

Para ahli filsafat pendidikan juga menyatakan bahwa dalam merumuskan esensi pendidikan sebenarnya sangat tergantung kepada pandangan terhadap manusia; hakikat, sifat-sifat atau karakteristik dan tujuan hidup manusia itu sendiri. Perumusan pendidikan bergantung kepada pandangan hidupnya, "apakah manusia dilihat sebagai kesatuan badan dan jasmani; badan, jiwa dan roh, atau jasmani dan rohani? Apakah manusia pada hakekatnya dianggap memiliki kemampuan bawaan (innate) yang menentukan perkembangannya dalam lingkungannya, atau lingkungannyalah yang menentukan (domain) dalam perkembangan manusia? Bagimanakah kedudukan individu dalam masyarakat? Apakah tujuan hidup manusia? Apakah manusia dianggap hanya hidup sekali di dunia ini, ataukah hidup lagi di hari kemudian (akhirat)? Demikian beberapa pertanyaan filosofis" yang diajukan. ${ }^{3}$

\footnotetext{
${ }^{2}$ Abdul Manaf, Pendidikan bukan Untuk Penjajahan, Visipres, Surabaya, 2008, hal. 12.

${ }^{3}$ Hujair AH. Sanaky, Pembaharuan Pendidikan Islam Menuju Masyarakat Madani, [Tinjauan Filosofis], dalam Ali Komaruddin, Filsafat Pendidikan Islam. Gladios, Yogyakarta, 2015, hal. 1,
} 
PIWULANG: Jurnal Pendidikan Agama Islam, Vol. 3 No. 1 September 2020, 65-74

P-ISSN : 2622-5638. E-ISSN : 2622-5654

Homepage: http://e-journal.staima-alhikam.ac.id/index.php/piwulang

Penilaian itu mengisyaratkan, bahwa seseorang atau sekelompok orang yang berusaha mempelajari atau mengkaji masalah pendidikan berarti memasuki masalah proses, manajemen, atau transformasi dan ekspektasi yang mengikat perjalanan hidupnya maupun orang lain. Oleh karena itu, sebelum membicarakan esensi pendidikan Islam, maka perlu diketahui terlebih dahulu pemahaman pendidikan secara umum sebagai titik tolak memberikan memasuki ranah filosofi pendidikan Islam.

\section{2) Urgensi Pendidikan Islam}

Menurut paedagog M.J. Langeveld, bahwa pendidikan merupakan upaya manusia dewasa membimbing yang belum kepada kedewasaan. ${ }^{4}$ Pandangan Langeveld ini ringkas, namun mengandung makna yang dalam. Beda dengan ini, Ahmad D.Marimba merumuskan pendidikan merupakan bimbingan atau pimpinan secara sadar oleh si pendidik terhadap perkembangan jasmani dan rohani si terdidik menuju terbentuknya kepribadian yang utama. ${ }^{5}$ Pemikiran Marimba ini menunjuk tentang suatu proses yang berorientasi pada hasil. Dalam proses ini Marimba melibatkan dua pihak (pendidik dan peserta didik), yang kemudian dari proses ini menghasilkan terbentuknya kepribadian manusia utama. Manusia utama yang dituju sebagai hasil dari proses ini tentu tekanannya pada kualitas proses, yang dari kualitas ini menghasilkan sumberdaya manusia berkualitas.

Dalam pasal 1 angka 1 Undang-undang Nomor 20 Tahun 2003 tentang Sistem Pendidikan Nasional, bahwa pendidikan adalah usaha sadar dan terencana untuk mewujudkan suasana belajar dan proses pembelajaran agar peserta didik secara aktif mengembangkan potensi dirinya untuk memiliki kekuatan spiritual keagamaan, pengendalian diri, kepribadian, kecerdasan, akhlak mulia, serta ketrampilan yang diperlukan dirinya, masyarakat, bangsa, dan negara. ${ }^{6}$ Berdasarkan norma yang digariskan UUP ini, maka sudah jelas bahwa jika dibaca secara filosofis, pendidikan yang diselenggarakan oleh penyelenggara bermaksud mulia, yang bukan hanya berorientasi membentuk kemampuan sumberdaya manusia (peserta didik) sehingga mempunyai ketrampilan tertentu, tetapi juga berkepribadian unggul secara etis dan spirtualitas.

\footnotetext{
${ }^{4}$ Ali Komaruddin, Filsafat Pendidikan Islam..., hal. 2

${ }^{5}$ Ali Komaruddin, Filsafat Pendidikan Islam .... hal. 3.

${ }^{6}$ Undang-undang Republik Indonesia Nomor 20 Tahun 2003 tentang Sistem Pendidikan Nasional, Jakarta: Citra Umbara, 2003.
} 
PIWULANG: Jurnal Pendidikan Agama Islam, Vol. 3 No. 1 September 2020, 65-74

P-ISSN : 2622-5638. E-ISSN : 2622-5654

Homepage: http://e-journal.staima-alhikam.ac.id/index.php/piwulang

Pendidikan seperti itu dapat disebut pula sebagai suatu usaha sadar dan teratur serta sistematis, yang dilakukan oleh orang-orang yang bertanggung jawab, untuk mempengaruhi anak (peserta didik) agar mempunyai sifat dan tabiat sesuai dengan cita-cita pendidikan. Pendidikan adalah bantuan yang diberikan dengan sengaja kepada anak, dalam pertumbuhan jasmani maupun rohani untuk mencapai tingkat dewasa. ${ }^{7}$ Idealitas ini sejalan dengan esensi pendidikan sebagaimana yang digariskan dalam UUP.

Seorang tokoh pendidikan Herman H. Home berpendapat bahwa pendidikan harus dipandang secara timbal balik dengan alam sekitar, dengan sesama manusia dan dengan tabiat tertinggi. ${ }^{8}$ Dalam keanekaragaman pandangan tentang pendidikan terdapat titik-titik persamaan tentang pengertian pendidikan, yaitu pendidikan dilihat sebagai suatu proses; karena dengan proses itu seseorang (dewasa) secara sengaja mengarahkan pertumbuhan atau perkembangan seseorang (yang belum dewasa). Proses adalah kegiatan mengarahkan perkembangan seseorang sesuai dengan nilai-nilai yang merupakan jawaban atas pertanyaan-pertanyaan tersebut di atas. Maka, dengan pemahaman ini, kegiatan atau proses pendidikan hanya berlaku pada manusia tidak pada hewan. ${ }^{9}$ Manusia berposisi sebagai subyek yang menentukan dan ditentukan dalam pendidikan. Peserta didik memang bukan obyek atau bukan pula sebagai pihak yang ditentukan, melainkan sebagai subyek yang ikut membentuk dan menetukan dirinya.

Pemahaman mengenai pendidikan, orang-orang Yunani, lebih kurang 600 tahun sebelum Masehi, telah menyatakan bahwa pendidikan ialah usaha manusia untuk menjadi manusia. Ada dua kata yang penting dalam kalimat itu, pertama "membantu" dan kedua "manusia". Manusia perlu dibantu agar menjadi manusia. Seseorang dapat dikatakan telah menjadi manusia bila telah memiliki nilai (sifat) kemanusiaan. Hal ini menunjukkan bahwa tidaklah mudah menjadi manusia. Karena itulah sejak dahulu manusia gagal menjadi manusia. Jadi, tujuan mendidik ialah memanusiakan manusia. Agar tujuan itu dapat dicapai dan agar progam dapat disusun, maka cici-ciri manusia yang telah menjadi manusia itu haruslah jelas. ${ }^{10}$ Tujuan Pendidikan dengan menjadikan seperti "memanusiakan" manusia memang lebih

\footnotetext{
${ }^{7}$ M. Amin, Pengantar Ilmu Pendidikan Islam, PT. Garoeda Buana Indah, Pasuruan: 1992,hal.1

8 M. Arifin, Filsafat Pendidikan Islam, Bina Aksara, Jakarta: 1987, hal.11

${ }^{9}$ Anwar Jasin, Kerangka Dasar Pembaharuan Pendidikan Islam : Tinjauan Filosofis, Jakarta. 1985, hal. 2.

${ }^{10}$ Ahmad Tafsir, Filsafat Pendidikan Islam,: Remaja Rosdakarya, Bandung 2006, hal.33
} 
PIWULANG: Jurnal Pendidikan Agama Islam, Vol. 3 No. 1 September 2020, 65-74

P-ISSN : 2622-5638. E-ISSN : 2622-5654

Homepage: http://e-journal.staima-alhikam.ac.id/index.php/piwulang

ringkas, namun maknanya sangat luas. Bagaimana caranya "memanusiakan" manusia, apalagi di era yang terkadang melupakan manusia kalua dirinya adalah manusia.

Pemikiran manusia terhadap masalah-masalah kependidikan untuk memecahkan dan menyusun teori-teori baru dengan mendasarkan kepada pemikiran normatif, spekulatif, rasional empirik, rasional filosofik maupun historik filosofik. Sedangkan pendidikan dalam arti praktek, adalah suatu proses pemindahan atau transformasi pengetahuan ataupun pengembangan potensi-potensi yang dimiliki subjek didik untuk mencapai perkembangan secara optimal, serta membudayakan manusia melalui transformasi nilai-nilai yang utama. ${ }^{11}$

Fokus pendidikan yang mampu menanamkan ajaran Islam dengan menjadikan manusia yang sesuai dengan cita-cita Islam yang berorientasi pada dunia akhirat. Adapun dasar yang menjadikan acuan pendidikan Islam merupakan sumber nilai kebenaran dan kekuatan yang mengantarkan kepada kreativitas yang dicita-citakan. Nilai-nilai yang terkandung harus mencerminkan ruang universal dan yang dapat mengevaluasi kegiatan aspek manusia, serta merupakan standar nilai yang dapat mengevaluasi kegiatan yang sedang berjalan.

Memahami itu, Omar Muhammad At-Toumy al-Syaebany, menyebut pendidikan Islam sebagai usaha mengubah tingkah laku individu dalam kehidupan pribadinya atau kehidupan kemasyarakatannya dan kehidupan dalam alam sekitarnya melalui proses kependidikan. ${ }^{12}$ Pendidikan Islam adalah suatu pendidikan yang melatih perasaan murid-murid dengan cara begitu rupa sehingga dalam sikap hidup, tindakan, keputusan, dan pendekatan mereka terhadap segala jenis pengetahuan, mereka dipengaruhi sekali oleh nilai spritual dan sangat sadar akan nilai etis Islam. ${ }^{13}$ Mengubah keadaan dalam multi aspek akibat tantangan di sekitar atau yang menyerang (mempengaruhi) peserta didik merupakan kondisi logis yang memang dihadapi oleh siapapun yang oleh komunitas manapun, karena justru ketahanan suatu aktifitas dilihat atau diukur dari kemungkinan besaran atau beratnya tantangan yang dihadapinya.

Pendidikan Islam yang menekankan pada aspek proses dan terjadinya transformasi nilai-nilai kebenaran yang bertujuan membentuk manusia unggul (punya kepribadian yang sarat pemahaman, pengimplementasian, dan pengembangan doktrin luhur),

${ }^{11}$ Chabib Thoha, Kapita Selekta Pendidikan Islam, Pustaka Pelajar, Yogyakarta: 1996, hal. 9899

12 M.Arifin, Filsafat Pendidikan Islam..., hal. 11

${ }^{13}$ Syed Sajjad Husain dan Syed Ali Ashraf, Crisis Muslim Education.,. hal. 2. 
PIWULANG: Jurnal Pendidikan Agama Islam, Vol. 3 No. 1 September 2020, 65-74

P-ISSN : 2622-5638. E-ISSN : 2622-5654

Homepage: http://e-journal.staima-alhikam.ac.id/index.php/piwulang

merupakan proses edukatif yang dapat menentukan wajah peradaban dunia.

\section{3) Memprogresivitas Sumberdaya Manusia Era Pandemi Covid}

Ada teori progresivitas pendidikan yang dikonstruksi Brubacher, yang mengatakan"Education is the organized development and equipment of all the powers of a human being, moral, intellectual and physical, by and for their individual and social uses, directed toward the union of these activities with their creator as their final and" Artinya: "Pendidikan merupakan perkembangan yang terorganisir dan kelengkapan dari semua potensi manusia, moral, intelektual maupun jasmani, oleh dan untuk kepribadian individunya dan kegunaan masyarakatnya, yang diarahkan untuk menghimpun semua aktivitas tersebut bagi tujuan hidupnya yang akhir".14

Pemikiran Brubacher itu sejalan dengan pemikiran S. Mardiatmadja pendidikan merupakan suatu usaha bersama dalam proses terpadu (terorganisir) untuk membantu manusia mengembangkan diri dan menyiapkan diri guna mengambil tempat semestinya dalam pengembangan masyarakat dan dunianya dihadapan Sang Pencipta. Dengan proses itu, seorang manusia dibantu untuk menjadi sadar akan kenyataan-kenyataan dalam hidupnya, bagaimana dimengerti, dimanfaatkan, dihargai, dicintai, apa kewajiban-kewajiban dan tugas-tugasnya agar dapat sampai kepada alam, sesama, dan Tuhan, sebagai tujuan hidupnya. ${ }^{15}$

Sahal Mahfud menyebut, bahwa pendidikan pada dasarnya merupakan usaha sadar yang membentuk watak dan perilaku secara sistematis, terencana dan terarah. ${ }^{16}$ Kalau pandangan Sahal Mahfud ini difokuskan pada pendidikan Islam, maka hal ini mengidentikkan kalau penyelenggaraannya tetap harus progresif, dan bukannya malah berjalan stagnan dan mundur. Pembentukan watak dan perilaku ini tidak mudah, karena pandemi Covid-19 ini mereduksi dan bahkan menguras kemampuan atau ketahanan banyak subyek bangsa ini.

Sumberdaya manusia memang harus terus diprogresifitaskan, baik dari sisi peserta didik maupun penyelenggaranya, apalagi dalam lingkup pendidikan Islam keduanya akan saling menetukan hasilnya. Jika keduanya tidak progresif dalam menyikapi eksaminasi pandemic

\footnotetext{
${ }^{14}$ M. Tholhah Hasan, Islam dalam Perspektif Sosial Budaya, Galasa Nusantara, Jakarta:, 1987, Hal. 16-17.

15 BS. Mardiatmadja, Tantangan Dunia Pendidikan,: Kanisius, Yogyakarta 1986, hal. 19

${ }^{16}$ Sahal Mahfud, Nuansa Fiqh Sosial,: LKIS, Yogyakarta 1994, hal. 257.
} 
PIWULANG: Jurnal Pendidikan Agama Islam, Vol. 3 No. 1 September 2020, 65-74

P-ISSN : 2622-5638. E-ISSN : 2622-5654

Homepage: http://e-journal.staima-alhikam.ac.id/index.php/piwulang

Covid-19, maka kerugian besar bisa menimpa masyarakat dan bangsa, khususnya dunia pendidikan Islam.

Akibat pandemi Covid-19 memang sudah mengubah wajah dunia pendidikan Islam, terutama dari sisi pengimplementasian proses pembelajarannya, seperti cara berrelasi dan berkomunikasi, serta evaluasinya, disamping kurikulumnya, akan tetapi menciptakan kondisi progresif tetaplah harus dilakukan. Tanpa upaya memprogresifitaskan ini, progresifitas pendidikan yang menghasilkan sumberdaya manusia unggul sulit diharapkan terwujud.

Eksistensi pendidikan merupakan usaha dan kegiatan yang berproses melalui tahap-tahap dan tingkatan-tingkatan, tujuannya bertahap dan bertingkat. Tujuan pendidikan bukanlah suatu benda yang berbentuk tetap dan statis, tetapi ia merupakan suatu keseluruhan dari kepribadian seseorang, berkenaan dengan seluruh aspek kehidupannya. ${ }^{17}$ Eksistensi ini identik dengan konstruksi pendidikan Islam, yang memang dalam penyelenggarannya harus dilaksanakan secara bertahap. Dari tahapan inilah bisa diketahui titik kurang dan lebih dari setiap perkembangan, sehingga sumberdaya manusia dari sisi peserta didik dapat dikondisikan untuk beradaptasi supaya dalam menyikapi (menjawab) progresifitas berikutnya tidak sampai mengalami kesulitan besar.

Langkah itu mempertimbangkan fenomena beratnya yang dihadapi oleh peserta didik di era pandemi Covid-19 yang berfikir atau bersikap pragmatis dengan menempatkan proses pembelajaran yang dijalankan selama era pandemi Covid-19 tidak atau belum menampakkan hasil yang baik. Bersumber dari peserta didik ini kemudian menempatkan proses pembelajaran sebagai aktifitas yang "sekedar ada" supaya bisa dijadikan alasan menghasilkan penilaian (angka).

Suatu proses pembelajaran yang "sekedar ada" dapat dikategorikan sebagai pelanggaran hak edukatif peserta didik, karena ini berarti kehadiran atau eksistensinya tidak ubahnya sekedar pelapis berjalannya sistem yang diterapkan. Mereka membutuhan suatu proses yang barangkali dapat menyegarkan suasana, membuat psikologis tersentuh, atau kondisi yang sedang dialami ini tidak terlalu menyiksa.

Dalam Pasal 9 huruf (b) Deklarasi Kairo disebutkan, bahwa setiap manusia mempunyai hak untuk mendapatkan dua hal, agama dan dunia pendidikan dari berbagai lembaga pendidikan dan bimbingan, di dalam keluarga, sekolah, universitas, media, dan lain-lain.

17Zakiyah Drajat, Ilmu Pendidikan Islam, Bumi Aksara, Jakarta: 2004, hal. 29 
PIWULANG: Jurnal Pendidikan Agama Islam, Vol. 3 No. 1 September 2020, 65-74

P-ISSN : 2622-5638. E-ISSN : 2622-5654

Homepage: http://e-journal.staima-alhikam.ac.id/index.php/piwulang

Dan semua itu dipadukan dan diseimbangkan caranya untuk mengembangkan kepribadiannya, memperkuat ketakwaan kepada Tuhan dan meningkatkan penghargaan untuk pembelaan hak-hak dan kewajibannya.

Dari Deklarasi Cairo (Islam), secara tidak langsung mengingatkan setiap penyelenggara pendidikan Islam, bahwa setiap peserta didik mempunyai hak memprogresifitaskan (mengembangkan) dirinya. Progresifitas ini harus ditandai dengan adanya perubahan yang bermakna bagi peserta didik. Disinilah kata kuncinya, bahwa memprogresifitas diri di tengah pandemi Covid-19 menunggu kerja keras dan cerdas penyelenggara edukasinya. Membentuk peserta didik supaya mempunyai optimisme dalam menghadapi ujian pandemi Covid-19 merupakan langkah edukatif penuh strategis dengan mempertimbangkan kondisi psikologisnya.

\section{PENUTUP}

Salah satu pihak yang seringkali menghadapi kondisi sulit adalah para penyelenggara pendidikan ketika ada perubahan besar dalam kehidupan masyarakat dan bangsa. Masih tingginya perkembangan pandemi Covid-19 adalah salah satu kasus yang membuat dunia pendidikan, tidak terkecuali pendidikan Islam mengalami perubahan, karena harus mengikuti perubahan sosialnya.

Dalam ranah itu, memang tidak ada masyarakat dan bangsa di dunia ini, termasuk Indonesia yang tidak menganggap pendidikan ini penting (urgen), sehingga dalam menghadapi kondisi apapun yang menimpa masyarakat dan bangsa ini, ketergantungannya pada pendidikan sebagai kebutuhan tetaplah sangat tinggi, yakni diperuntukkan bagi pembentukan sumberdaya manusia. Dari sumberdaya manusia yang terbentuk ini, masyarakat dan bangsa bisa menunjukkan ekspektasinya, bahwa masih banyak hal yang bisa diperbuat atau dikembangkan untuk dan demi kepentingan sumberdaya manusia itu.

\section{DAFTAR PUSTAKA}

Abdul Manaf, 2008, Pendidikan bukan Untuk Penjajahan, Surabaya: Visipres. Ahmad Tafsir, 2006, Filsafat Pendidikan Islam, Bandung; Remaja Rosdakarya. Ali Komaruddin, 2015, Filsafat Pendidikan Islam. Yogyakarta: Gladios. 
PIWULANG: Jurnal Pendidikan Agama Islam, Vol. 3 No. 1 September 2020, 65-74 P-ISSN : 2622-5638. E-ISSN : 2622-5654 Homepage: http://e-journal.staima-alhikam.ac.id/index.php/piwulang

Anwar Jasin, 1985, Kerangka Dasar Pembaharuan Pendidikan Islam: Tinjauan Filosofis, Jakarta: Anugerah

BS. Mardiatmadja, 1986, Tantangan Dunia Pendidikan: Yogyakarta: Kanisius.

Chabib Thoha, 1996, Kapita Selekta Pendidikan Islam, Pustaka Pelajar: Yogyakarta

M. Amin, 1992, Pengantar Ilmu Pendidikan Islam, Pasuruan: PT. Garoeda Buana Indah.

M. Arifin, 1987, Filsafat Pendidikan Islam, Jakarta: Bina Aksara.

M. Tholhah Hasan, 1987, Islam dalam Perspektif Sosial Budaya, Jakarta: Galasa Nusantara.

Sahal Mahfud, 1994, Nuansa Fiqh Sosial, Yogyakarta: LKIS.

Syed Sajjad Husain dan Syed Ali Ashraf, 1986, Crisis Muslim Education., Terj. Rahmani Astuti, Krisis Pendidikan Islam, Surabaya: Risalah.

Undang-undang Republik Indonesia Nomor 20 Tahun 2003 tentang Sistem Pendidikan Nasional, Jakarta: Citra Umbara,

Zakiyah Drajat, 2004, Ilmu Pendidikan Islam, Bumi Aksara, Jakarta: 2004. 